\title{
JUVENTUDE URBANA E REDES SOCIAIS EM MOÇAMBIQUE: A PARTICIPAÇÃO POLÍTICA DOS CONECTADOS DESAMPARADOS
}

\author{
Dércio Tsandzana
}

\begin{abstract}
Resumo
Nos últimos 10 anos, os estudos sobre a participação política por intermédio das redes sociais marcam o debate na área dos estudos dos média. Em Moçambique, de forma particular, e no mundo, de forma geral, a juventude representa o centro galvanizador que encontra no uso das redes socias uma ferramenta quase ideal de expressão sobre as suas frustrações decorrentes da sua situação de gritante miséria social - desemprego e incerteza de vida constante a que os jovens se encontram expostos. Com o presente artigo, pretendemos analisar o papel das redes sociais, concretamente o Facebook, no engajamento político e social da juventude urbana em Moçambique, considerando um horizonte que abarca os últimos quatro anos, 2014-2017. Como resultado, concluímos que embora a sua expansão nos últimos anos, as redes sociais ainda não podem ser consideradas, no seu todo, como espaços que permitam uma efectiva participação política da juventude, decorrente do facto de a internet ser menos abrangente, por um lado, e do fraco interesse da juventude em questões políticas em Moçambique, por outro.
\end{abstract}

\section{URBAN YOUTH AND SOCIAL NETWORKS IN MOZAMBIQUE: THE POLITICAL PARTICIPATION OF THE HELPLESS CONNECTED}

\begin{abstract}
In the last 10 years, studies on political participation through social networks have marked the debate in the field of media studies. In Mozambique, particularly, and in the world, in general, youth represent the galvanizing centre that finds in the use of social networks an almost ideal tool of expression about their frustrations due to their situation of blatant social misery - unemployment and constant life uncertainty to which youth are exposed. With this article, we intend to analyse the role of social networks, specifically Facebook, in the political and social engagement of urban youth in Mozambique, considering a timeline that covers the last four years, 2014 to 2017. As a result, it is concluded that, despite the expansion of social networks in recent years, they cannot yet be considered as spaces for effective political participation by youth, due to the fact that the internet is less comprehensive, on the one hand, and the weak youth interest in political issues in Mozambique, on the other.
\end{abstract}




\section{INTRODUÇÃO}

Actualmente, com a crescente desconfiança sobre os métodos tradicionais de participação política baseados no voto, os níveis de abstenção eleitoral e o fraco engajamento pela política usual mostra-se em alta, praticamente, em todo o mundo. Porém, em contrapartida, a emergência das redes sociais representa a abertura de um espaço dinâmico com novas formas de participação cívico-política.

No presente artigo, um dos primeiros elementos a ter em conta é o da compreensão do que consideramos participação política, uma discussão que, no seio das ciências sociais não colhe consenso, segundo Norris (2003). Porém, julgamos antes ser necessário definir o termo 'participação' que, para além de ser polissémico, autores como Bordenave (1983, p. 23) consideram que o mesmo significa "fazer parte, tomar parte ou ter parte". O autor prossegue dizendo que de nada adianta "fazer parte" sem "tomar parte", como, por exemplo, alguém que faz parte de um grupo, mas não toma parte das decisões do mesmo. Em termos políticos, podemos afirmar que a participação é vista como "o conjunto de actividades individuais ou colectivas que podem influenciar os governados sobre o funcionamento do sistema político", como aponta Braud (2014, p. 353). Por outro lado, Nay (2014, p. 419), afirma que a participação política é

o conjunto de práticas (voto, protesto, activismo e participação em reuniões públicas), bem como manifestações de interesse (para aprender sobre política ou falar de política) dos governantes e dos cidadãos em relação aos assuntos públicos que afectam a comunidade, a região, o Estado ou mesmo toda a humanidade.

Para nós, a definição de Nay (2014) é interessante, visto que destaca, para além da votação, o activismo político como uma das formas integradas na participação política. No campo da ciência política, o voto ainda é reconhecido como a modalidade essencial de participação política, o que podemos chamar de "boa participação". Porém, nos últimos anos regista-se o surgimento de novas formas de participação que se materializam em movimentos e organizações sociais, por intermédio de outras práticas como: realização de greves, boicotes, petições e manifestações com vista a influenciar os governos, o que podemos chamar de "má participação". Esta tendência é derivada do esgotamento político por parte dos cidadãos e consequente decepção com o voto como o único mecanismo de participar politicamente, como aponta Dahlgren (2003). Assim, as redes sociais e outras formas de comunicação virtual mostram-se como essenciais, porque permitem a troca de informação com as contrapartes e com uma população desinformada. De acordo com Castells (2001, p. 9), "uma rede é um conjunto de ligações interconectadas - modos de organização com benefícios extraordinários, porque eles são naturalmente flexíveis e adaptáveis, qualidades essenciais para sobreviver e prosperar em um ambiente em rápida mudança". Mais amplamente, uma rede social pode ser uma estrutura social da internet, em que os elementos são constituídos por organizações ou indivíduos, e cujos elos representam as interações estabelecidas (político, corporativo, de serviço, familiar, amigável, de acordo com o interesse e assim por diante). A principal 
função de cada rede é, acima de tudo, a comunicação em massa e a transmissão de conhecimentos que serão examinados em maior detalhe em nossa pesquisa.

Por um lado, autores como Matos (2009) mostram-nos que as redes sociais podem ser um conjunto de espaços físicos e imateriais, onde os agentes sociais podem efectivar sua participação no processo de comunicação pública, uma demostração que interessa estudar no presente artigo. Já Pereira (2011, p. 16) explica que o potencial da internet concentra-se em

atingir indivíduos que, a princípio sem vinculações políticas às instituições clássicas de organização da sociedade civil, estejam dispostos, desde que sejam 'devidamente' convencidos, a participar de acções específicas de protesto, cibernéticas ou não, que tenham alguma identidade com seus interesses e percepções de mundo.

Destacamos aqui como exemplo que desde a primavera árabe', é cada vez mais recorrente observar que os jovens, em vários cantos do mundo, têm usado a tecnologia para se mobilizarem em torno das questões que os afectam. Por um lado, tal como afirma Luvizotto (2016, p. 301), com a internet e as redes sociais, as formas de comunicação e consumo de informação se modificaram, deixando de ser unilaterais - marca dos meios de comunicação de massa - e passam a ser mais participativas e democráticas. Ou seja, a informação circula com maior fluidez e o seu alcance é amplo, se comparado com outras ferramentas de média. Para além de diminuir a distância e o custo, a internet (com destaque para as redes sociais como o Facebook), revolucionou a forma como a comunicação é exercida, sendo que os actores políticos tentam capitalizar amplamente esse fenómeno, mesmo considerando os últimos escândalos - como é o caso da Cambridge Analytica (CA ${ }^{2}$.

Por outro, as redes sociais dão origem a novas transformações em nossas vidas diárias, de forma dinâmica, e em constante mudança. Aqui, referimo-nos concretamente ao fenómeno designado uberização, que é amplamente aclamado pelos jovens que encontram um espaço ideal e um discurso de rebelião contra o velho mundo que não dá espaço suficiente para eles, segundo Larrouy (2017, p. 56). Na mesma dimensão, observa-se o surgimento do chamado "jornalismo-cidadão"' uma prática que desempenha um papel fundamental para o crescente desenvolvimento da participação política e cívica dos cidadãos por intermédio de blogs e fóruns de debate no Facebook, Twitter e em outras plataformas de interacção (som, escrita, imagem).

Ao longo do artigo, vamos concentrar-nos na análise sobre os contornos da participação cívica e política da juventude urbana de duas cidades de Moçambique por

\footnotetext{
' Foi uma onda revolucionária de manifestações e protestos que ocorreram no Médio Oriente e no Norte da África a partir de 18 de Dezembro de 2010. De forma concreta houve revoluções na Tunísia e no Egipto.

2 Em 2016, a CA trabalhou para a campanha presidencial de Donald Trump e também para a do Brexit, visando a saída do Reino Unido da União Europeia.

3 Ver o movimento Olho do Cidadão-Txeka em Moçambique, constituído por jovens bloguistas que usam as redes sociais para monitorar a governação.
} 
intermédio das redes sociais, concretamente o Facebook, num horizonte compreendido de quatro anos (2014-2017), designadamente, as Cidades de Maputo e da Beira, dois centros urbanos que marcam o cenário político moçambicano, sendo que a Cidade de Maputo encontra-se sob governação do partido no poder, Frente de Libertação de Moçambique - Frelimo, e a cidade da Beira sob gestão do partido da oposição, Movimento Democrático de Moçambique - MDM. Além desse facto, historicamente, a Cidade da Beira representa um espaço fervescente do debate político nacional - o bastião da oposição.

A escolha de 2014 como ponto de partida deve-se ao facto de ter sido naquele ano em que se assistiu a um interesse particular, por parte dos políticos, em usar as redes sociais como espaço de engajamento aos cidadãos, concretamente durante a campanha eleitoral para as quintas eleições gerais em Moçambique, realizadas no dia 15 de Outubro daquele ano. Para a sua efectivação, o presente estudo observou a realização de uma pesquisa qualitativa coadjuvada pela administração de entrevistas semiestruturadas através de grupos focais com jovens de seis organizações cívicas em Maputo e Beira, bem como a revisão bibliográfica baseada nos estudos sobre o associativismo juvenil em Moçambique e no debate teórico sobre participação política e redes sociais. Das organizações envolvidas no estudo, destaca-se o Parlamento Juvenil de Moçambique - coordenação da Cidade de Maputo e Beira, e Activista Moçambique e Olho do Cidadão/Txeka, ambas da Cidade de Maputo. Na Beira, foram entrevistados elementos das Associações Coalizão, É Possível e AJURIS - Jovens Unidos Rumo à Reintegração Social.

Formalmente, o artigo está dividido em quatro partes, na primeira, apresenta-se um breve resumo sobre a situação da juventude e governação da internet no espaço lusófono; na segunda, faz-se a fundamentação teórica que orienta a problematização do tema; na terceira, procura-se fazer um enquadramento das dinâmicas da participação política na realidade africana e no caso moçambicano; na quarta e última parte, avançam-se as principais conclusões desta investigação em forma de pistas de análise e hipóteses.

\section{BREVE ENQUADRAMENTO SOBRE A JUVENTUDE E A GOVERNAÇÃO DA INTERNET NO ESPAÇO LUSÓFONO}

Uma das grandes dificuldades metodológicas, quando discutimos sobre a internet, é a existência de uma divergência acentuada na uniformização dos dados sobre o acesso à mesma. Porém, no que aos países da CPLP diz respeito, podemos afirmar que o Brasil e Portugal aparecem como aqueles que se encontram bem posicionados, dadas as condições económicas e infra-estruturais em comparação com os outros países da comunidade. Sendo Moçambique o nosso interesse particular, cabe-nos notar que o acesso à internet situa-se em apenas $18 \%{ }^{4}$ do total população (29 milhões de habitantes5).

No espaço da CPLP, a realização das Conferências de Governação Electrónica, constituem um espaço privilegiado em que a discussão de questões ligadas à internet

${ }_{4}$ Retirado de https://hootsuite.com/pt/pages/digital-in-2018

${ }_{5}^{5}$ De acordo com informação do INE - Instituto Nacional de Estatísticas de Moçambique, 2017, disponível em http://www. ine.gov.mz/ 
é tida em conta, tendo a última decorrido em Outubro de 2017, no Brasil. A este evento junta-se o Fórum da CPLP sobre Cibersegurança, cujo objectivo é desenvolver uma reflexão em conjunto sobre a segurança da informação nesta era digital, promovendo a cooperação multilateral entre Estados-membros na área das telecomunicações, tendo o último encontro sido realizado em Díli, Timor-Leste.

Por outro lado, podemos destacar o surgimento da primeira iniciativa Lusófona do Fórum de Governação da Internet ${ }^{6}$, cuja realização teve lugar no segundo trimestre de 2018. Porém, precisamos recuar para o ano 2014 quando assistimos à aprovação da Declaração NETmundial, no Brasil, um instrumento que resultou da discussão sobre o papel de vários actores na governação da internet. Os exemplos acima configuram uma demostração que o espaço lusófono ganha um maior interesse ao se preocupar não só em debater o futuro da internet, mas também com o papel de cada actor no processo da sua governação. Com estas iniciativas, percebe-se que o debate sobre a internet ganha maior destaque no seio da comunidade, embora, no cômputo geral, os países lusófonos não figurem como melhores classificados no acesso à internet no mundo.

No que tange à juventude, é preciso reconhecer que o seu estudo não é um exercício consensual no campo das ciências sociais, sobretudo quando existe uma grande divergência conceptual sobre a temática. $\mathrm{Na}$ vasta literatura consultada, observamos que ser jovem nem sempre significou o mesmo em todos os momentos, como é destacado por Muxel (1995), Abbnik (2005) e Galland (2009). Como sublinha Honwana (2012), a juventude é sobretudo uma construção histórica relacionada principalmente às transformações que afectam a sua socialização e a educação.

No entanto, cabe-nos sublinhar que não é apenas uma produção histórica, é também uma produção cultural e institucional, cujos contornos variam de acordo com as fronteiras nacionais e áreas culturais. Para o nosso estudo, consideraremos jovem todo aquele indivíduo a partir da faixa dos dezoito anos de idade - a idade legal para exercer o direito de voto em Moçambique, embora o acesso aos SNS (Social Networking Sites), regido pela lei federal americana, estabeleça a idade mínima de 13 anos para aceder ao Facebook, por exemplo. No tocante à CPLP, nota-se a realização de diferentes iniciativas e plataformas de interacção, com destaque para o Fórum da juventude da CPLP, de onde emerge a semana da juventude da CPLP, sendo que a última edição decorreu em Cascais (2017) sob o lema "Investir na Juventude", uma iniciativa que enquadra-se na Carta da juventude da CPLP (aprovada em Dezembro de 2013, em Salvador, no Brasil)7, a qual afirma no seu preâmbulo:

os Estados membros da CPLP reconhecem os jovens como sujeitos de direitos e sujeitos políticos, assumem como sua obrigação a promoção dos direitos, das políticas de inclusão, autonomia e emancipação, o desenvolvimento integral e o diálogo intergeracional como instrumentos para a afirmação dos jovens e dos seus projetos de vida. (...) A CPLP considera que os

\footnotetext{
${ }^{6}$ Trata-se do IGF - Lusofonia, Fórum de Governação da Internet, disponível em http://igf-lusofonia.pt/

7 Retirado de https://goo.gl/u2E99B
} 
jovens constituem um núcleo social com características próprias exigindo uma intervenção própria por parte dos poderes públicos, garantindo a participação dos jovens na tomada de decisões públicas.

A citação acima mostra, claramente, que existe uma consciência política ao mais alto nível sobre o papel que a juventude representa no seio da comunidade, embora variadas vezes seja relegada para o segundo plano pelos governantes, uma temática que iremos discutir na terceira parte do artigo.

\section{PARTICIPAÇÃo POLÍ́TICA (ONLINE) E SUAS LIMITAÇões}

Em um estudo realizado sobre activismo, participação política e internet, Luvizotto (2016, p. 302), explica que a internet e as redes sociais possibilitam uma nova compreensão e sentido para a participação, para a democracia, para o activismo e para as identidades colectivas. Essa ideia é corroborada por Vedel (2011, p. 73), que afirma que "nas últimas duas décadas, a internet mudou muitos aspectos do nosso quotidiano, e a política não escapou dessas transformações. Seja para informar, discutir notícias, participar de certas acções colectivas (como assinar uma petição), muitas vezes usamos ferramentas digitais". Essas abordagens nos convidam a pensar na internet como uma ferramenta de mudança marcada por uma evolução permanente. Não podemos imaginar o futuro sem ela, pois, a sua mudança é volátil e transforma as relações humanas de forma substancial.

Enquanto isso, Mabi e Theviot (2014, p. 5), afirmam que "a multiplicação de dispositivos participativos mobilizando ferramentas digitais atraiu rapidamente o interesse de pesquisadores, produzindo uma importante literatura sobre a relação entre a internet e a política, particularmente em termos de participação cívica". Esta afirmação pode sugerir que os novos media reduzem a distância entre os líderes políticos e os seus eleitores, e é por essa razão que em Moçambique, regista-se uma tendência de adoptar novas tecnologias para se comunicar com os cidadãos. Ao nível mais alto da política moçambicana, um exemplo notável foi a decisão de Julho de 2017 do Presidente da República de Moçambique, Filipe Nyusi, em abrir um espaço na sua página do Facebook para interagir com os usuários com o formato de perguntas e respostas, um exercício visto como forma de captar as sensibilidades da juventude naquele espaço.

Em um artigo sobre a mobilização de jovens brasileiros em São Paulo para o transporte público, De Melo (2013) apontava que em países onde a pluralidade dos meios de comunicação não é garantida, a expansão da internet é uma vantagem, especialmente para jovens democracias como é o caso do Brasil, onde a internet pode se tornar um instrumento que promove o exercício da cidadania. Em Moçambique, um país que historicamente possui um passado de repreensão política devido à existência de partido único ou partido-Estado, o uso da internet tem aumentando a cada ano nas cidades, mas também nas áreas rurais, havendo assim um uso abrangente para expressar opiniões sobre vários tópicos e especialmente para influenciar decisões políticas, sendo que na Cidade de Maputo se encontra o maior número de usuários. 
Contudo, é preciso sublinhar que as redes sociais não substituem a prática política quotidiana, como é o caso do voto. Assim, consideramos que "fazer política" na esfera da comunicação virtual tem seus limites, pois, as redes sociais não são um fim em si, mas um instrumento. Por exemplo, Monnoyer-Smith (2011) aponta que cada nova tecnologia de comunicação traz uma novidade aos usuários e pode ser usada para diversos fins, de acordo com cada pessoa. Esta afirmação não pode ser entendida como um elemento isolado da realidade, porque toda nova tecnologia é implantada em uma sociedade específica e com uma configuração social, política e económica diferente, ou seja, devemos entender essa evolução em sede do contexto em que vamos estudá-la, e Moçambique não é excepção.

Naquilo que Morozov (2011) chama "net desilusion", mostra que as redes sociais estão longe de constituir espaços de consenso sobre a participação e mobilização política, pois não basta o seu acesso, torna-se importante dominar o uso, pois, quanto mais acesso se têm, vários países e dirigentes políticos preparam-se para controlar ou limitar o uso dessas redes sociais como instrumentos de participação política. Em um estudo sobre a juventude britânica e o uso da internet, Gerodimos (2008) demonstrou que existe um modelo na interação top-down dos jovens por intermédio dos websites cívicos, o que desencoraja a participação online e cria sentimentos de desamparo.

Ainda no campo das limitações, Loader (2011, p. 759), sublinha que "munidos com media sociais, os cidadãos não precisam mais ser consumidores passivos de propaganda política, informações governamentais ou informações de massa, mas podem partilhar perspectivas alternativas e publicar suas histórias, suas próprias opiniões". No entanto, o mesmo autor afirma que hoje, o impacto mais óbvio das redes sociais sobre a democracia pode ter sido a sua capacidade de "perturbar as práticas e instituições políticas tradicionais", para as quais é claramente necessário evitar optimismo utópico sobre a existência de uma "democracia digital".

Essas observações nos fazem pensar em duas grandes questões: (1) a real capacidade mobilizadora das redes sociais, pois, se falamos sobre a participação política online da juventude urbana, é necessário aferir até que ponto essas redes sociais são um acto de inclusão, sobretudo em duas cidades marcadas pelo acesso desigual a recursos, como é o caso de Maputo e da Beira; e (2) até que ponto as redes sociais podem ser consideradas como um instrumento de libertação ou intimidação política pelos governos, visto que há registo de tendências repreensivas contra vozes que se levantam contra a governação vigente no país.

\section{JUVENTUde PARTICIPAVA, MAS ESQUeCIDA PELO PODER POlÍ́tico: A NARRATIVA AFRICANA E O CASO DE MOÇAMBIQUe}

Segundo Mbembe (1985, p. 19), para a maioria dos Estados africanos, os jovens são "a ponta de lança da nação", "a garantia mais segura para o futuro", "o futuro no presente". Esse é um discurso amplamente usado em vários países e revela uma homogeneização do Estado que se recusa a reconhecer a pluralidade das condições em que vivem os 
jovens. Ou seja, vários Estados apontam, às vezes, para culpar, ameaçar ou adiar, ou às vezes, para bajular a juventude, usando registos do futuro para colocar os jovens como as esperanças de amanhã. Anteriormente, esses jovens foram percebidos como um grupo sensível a qualquer coisa que pudesse levar à desestabilização do Estado.

A tendência de politizar a juventude moçambicana esteve quase sempre presente nas declarações do primeiro presidente de Moçambique independente, Samora Machel, proferindo, na mesma época em que se criou a Organização da Juventude Moçambicana (OJM), a 29 de novembro de 1977, que a juventude constituía a "seiva da nação", uma amostra que revela a importância histórica que há muito tempo tem sido dada à juventude como um actor crucial na construção do país, sublinha Biza (2009). Recentemente, falando numa reunião do partido Frelimo (25 de Março de 2018), Filipe Nyusi, presidente deste partido que é, ao mesmo tempo, o Presidente da República, disse que os jovens devem estar atentos:

para acelerar a criação do bem-estar dos jovens, identificamos como necessidades essenciais e imediatas: educação e formação, acesso à saúde, habitação decente, emprego. (...) Afirmamos que o jovem moçambicano não pode continuar com medo ou alimentado por promessas imaginárias por parte de forças que nunca fizeram nada por elas. Essas forças pretendem impressioná-las ou manipulá-las ${ }^{8}$.

Porém, em Moçambique, a realidade nos revela que a juventude encontra-se numa situação de "marginalização permanente" (Parlamento Juvenil de Moçambique, 2014), sendo que a sua representatividade política continua diminuta nos órgãos de decisão do país, embora constitua a maioria da população total do país. Por exemplo, ao nível da Assembleia da República, observamos que dos 250 deputados, apenas 40 (16\%) é que foram eleitos para a qualidade de Deputados com idade igual ou abaixo dos 35 anos, segundo nos revelou o Gabinete da Juventude Parlamentar de Moçambique.

Face a esta situação de aparente abandono político, como refúgio, a juventude encontra nas redes sociais um espaço fértil para o exercício da sua cidadania, visto que o modelo por intermédio da votação e representação política encontra-se em crise. Junta-se a este facto, o elevar da abstenção que não é necessariamente sinónimo de indiferença, mas sim uma transmissão de desconfiança, protesto e descontentamento - uma mensagem política. Por exemplo, em Moçambique, a participação dos eleitores durante as primeiras eleições de 1994 (88\%) foi substituída nos últimos anos por indiferença e apatia. Por outras palavras, mais de metade dos eleitores registados ignorou as eleições de 2009 (56\%) e 2014 (52\%), das quais as cidades de Maputo e Beira não são excepção'10.

Autores como Tournier (2009, p. 17), enfatizam que essa abstenção entre os jovens decorre, em primeiro lugar, de sua situação social. Por seu turno, Galland (2009, p. 45)

\footnotetext{
${ }^{8}$ Excerto de uma reportagem da STV, retirado de https://www.youtube.com/watch?v=2MbQW2yKSo8

9 Informação recolhida em conversa com o Gabinete da Juventude parlamentar de Moçambique, em 2018.

${ }^{10}$ Os dados da abstenção foram obtidos através do que foi produzido pelos órgão de administração e gestão eleitorais em Moçambique.
} 
afirma que há uma desconfiança dos jovens para a política baseada essencialmente na sensação de que os políticos estão totalmente desconectados das realidades quotidianas dos cidadãos. Além disso, Coleman (2005) afirma que não são os jovens que estão desconectados da política, mas as instituições políticas que estão longe desses jovens. Estes jovens, através de práticas como as redes sociais, constroem sua própria cultura de participação online. Ou seja, as modalidades tradicionais de participação política da juventude tendem a ser rejuvenescidas com o uso das redes sociais.

\section{REDES SOCIAIS COMO ALTERNATIVA PARA A PARTICIPAÇÃo POLÍTICA DA JUVENTUdE EM MoÇAMBIQUe: os CASOS DE MAPUTO E DA Beira}

Ao longo dos últimos 10 anos, observamos que Moçambique vive uma dinâmica política marcada pela renovação da paisagem política no meio urbano com a ascensão ao poder pela oposição nas chamadas "cidades mais influentes do país", designadamente Beira e Quelimane (centro) e Nampula (norte), que hoje estão sob a presidência do Movimento Democrático de Moçambique (MDM) e do partido Renamo, respectivamente. O ambiente urbano, em Moçambique, tem sido foco de várias manifestações populares, com destaque para o ano de 2010 na cidade Maputo, com a realização da "revolta contra o custo de vida", um momento marcante que abriu uma nova página na história das mobilizações colectivas em Moçambique (Chaimite, 2014).

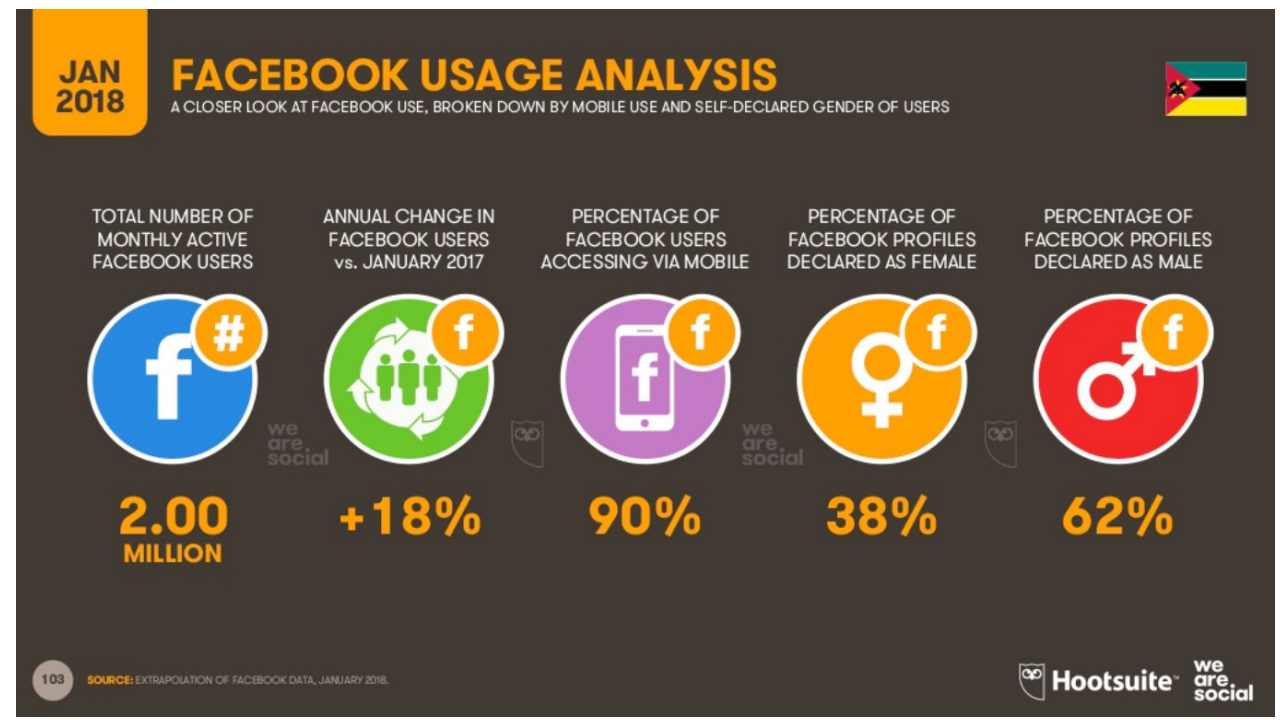

Figura 1: Número de usuários activos (mensalmente) de Facebook em Moçambique Fonte: https://hootsuite.com/pt/pages/digital-in-2018

Desde então, temos notado uma evolução do uso de vários espaços de participação para expressar uma opinião sobre diferentes assuntos concretos no quotidiano de Moçambique, uma tendência que contribuiu para o uso de tecnologias de informação e comunicação, com destaque para as redes sociais. De forma concreta, observamos imagens de jovens que se unem para protestar através do uso de hashtags pelo Twitter, 
Facebook e outras plataformas de redes sociais. O Facebook, em Moçambique, representa, de forma recorrente, um espaço galvanizador do engajamento da juventude, uma rede de dois milhões de utilizadores activos por mês" (Figura 1). Segundo Alexa (2018), o primeiro site mais visitado pelos moçambicanos é o Google, seguido pelo YouTube e pelo Facebook.

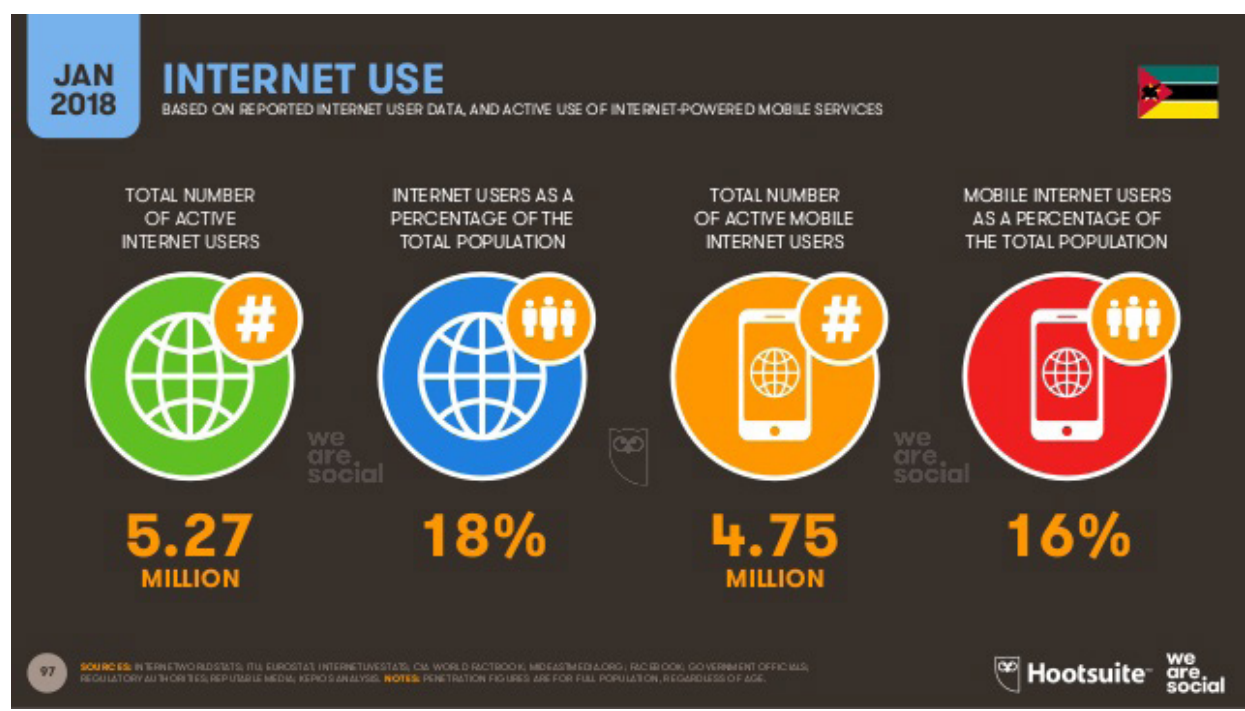

Figura 2: Número de usuários activos (mensalmente) de internet em Moçambique

Fonte: https://hootsuite.com/pt/pages/digital-in-2018

Considerando que apenas $18 \%$ da população possui acesso à internet ${ }^{12}$ (Figura 2) em Moçambique, importa referir que a televisão continua sendo o meio mais confiável para o acesso à informação, pois, de forma recorrente, os usuários buscam informação na internet, mas dão credibilidade após a sua certificação em um meio tradicional - canal de televisão ou rádio, segundo Raposo (2012). Esta realidade permite-nos entender em que dimensão devemos analisar a contribuição das redes sociais como espaços de práticas de participação política em uma sociedade marcada por uma desigualdade em termos de acesso e uso de novas tecnologias da informação e comunicação, bem como nos alerta para a necessidade de termos um olhar crítico sobre as mesmas redes.

Por um lado, a expansão exponencial no uso de redes sociais com serviços como Free Facebook'³ é fundamental para entender como esse crescimento tem trazido mudanças reais para a forma de participação na esfera política de Moçambique. Por outro lado, deve-se enfatizar que existe uma grande divergência geográfica entre as cidades em termos do desenvolvimento de infra-estruturas de provisão de serviços de internet, o que influencia de forma substancial a qualidade da mesma. Um dos casos de protestos sociais que teve o seu epicentro com o uso de redes sociais como ferramentas de

\footnotetext{
"Informação retirada de https://hootsuite.com/pt/pages/digital-in-2018

${ }^{12}$ Informação retirada de https://hootsuite.com/pt/pages/digital-in-2018

${ }^{13}$ Serviço implementado pela rede de telefonia móvel mCel com o apoio do Facebook.
} 
mobilização foi a manifestação realizada na cidade de Maputo, a 31 de Outubro de 2013, contra a insegurança pública, um acto que contou com uma participação de mais de 10 mil pessoas.

Outro exemplo de destaque foi a manifestação de 16 de Março de 2014, convocada por um grupo do Facebook intitulado Representantes de Luxo, cujo objectivo era de reivindicar contra as benesses dos Deputados da Assembleia da República. Ainda em 2014, durante a greve dos médicos (20 de Maio), a Associação dos Médicos de Moçambique utilizou o Facebook para publicar os seus comunicados de imprensa, tendo a detenção de Jorge Arroz, presidente da Associação de Médicos, sido anunciada primeiramente na página do Jornal@Verdade no Facebook'14 e, posteriormente, popularizada por outros meios de comunicação. Como resultado, registou-se a mobilização de mais de seiscentas pessoas para a esquadra da polícia para exigir a libertação do médico.

Já em 2015, as redes sociais voltaram a ser o epicentro da mobilização para uma manifestação contra o assassinato de um professor universitário no centro da Cidade de Maputo, bem como para a realização da "marcha popular pela paz", realizada em 2016. Estes exemplos revelam que as redes sociais começaram a constituir um campo de pressão, embora os políticos não tivessem, naqueles anos, a real dimensão dessa importância, a avaliar pela forma como reagiram - com espanto e chamando as redes sociais de "fábricas de sonhos inalcançáveis", como afirmara o então Presidente da República de Moçambique, Armando Guebuza.

Um exemplo notável, no campo político moçambicano, foi a decisão, em Julho de 2017, do Presidente da República de Moçambique, Filipe Nyusi, em abrir um espaço na sua página do Facebook 15 para interagir com os usuários da sua página num formato 'perguntas e respostas'. Por outro lado, Alcinda de Abreu, membro do bureau político do partido Frelimo, falando numa conferência realizada em 29 de Novembro de 2017, por ocasião do $40^{\circ}$ aniversário da Organização da Juventude de Moçambique, disse que o maior desafio da juventude de hoje é saber como usar as redes sociais para o acesso à informação e conhecimento, com o objectivo de desenvolver o país. Ainda em 2017, o presidente moçambicano convidou alguns jovens internautas ao palácio presidencial para uma interacção tête-à-tête, acto que repetiu já em 2018 durante uma visita de trabaIho realizada na Província de Inhambane, Sul de Moçambique.

De maneira geral, durante a nossa pesquisa, observamos que existem diferenças substanciais entre o entendimento sobre a participação da juventude nas redes sociais nas duas cidades. Enquanto em Maputo a juventude apresenta-se com alguma relativa liberdade para se expressar, na cidade da Beira constatamos que a apatia reina no seio da juventude, um elemento que é agravado pelas fortes desigualdades que se registam entre os bairros da mesma cidade.

Por exemplo, Jackson Timóteo, um dos nossos entrevistados na Beira, membro da Associação É Possível, referiu que a cultura de participação política varia de acordo com o bairro de residência e nível de escolaridade de cada jovem, tendo feito referência

\footnotetext{
${ }^{14}$ Disponível em https://www.facebook.com/JornalVerdade/

${ }^{15}$ Disponível em https://www.facebook.com/NyusiConfioemti/
} 
a Munhava e Macute, dois bairros residenciais onde as competências e qualidade de formação escolar dos jovens são diferentes, o que segundo ele influencia na forma como estes encaram e reagem aos problemas sociais e políticos:

se hoje queremos reivindicar alguma coisa, é mais fácil ir para Munhava do que ir para Macute. Aqueles que possuem mais necessidades vivem em Munhava e necessitam de ser ouvidos por quem de direito de acordo com suas necessidades - várias manifestações são feitas em Munhava e algumas são convocadas pelas redes sociais ${ }^{16}$.

Ainda na Cidade da Beira, Benedito Pequenino, coordenador da AJURIS fez notar que a entrada de um novo partido político, o Movimento Democrático de Moçambique - MDM, na governação municipal daquela cidade motivou a participação política dos jovens em questões locais, pois estes passaram a perceber que existe espaço para uma alternativa política, o que de igual forma trouxe abertura para a aceitação de novas ideias.

Concernente à Cidade de Maputo, Cídia Chissungo, do Activista Moçambique referiu que os jovens de Maputo pouco participam por intermédio das redes sociais devido ao percurso histórico e político do próprio país, pois acredita-se que aqueles que mais questionam os dirigentes estão tendencialmente expostos a perder oportunidades diversas, por essa razão "estão habituados a menos questionar e a ser bem-educados" Porém, tal como na Beira, Alexandre Nhampossa, do Olho do Cidadão-Txeka, revelou que na Cidade de Maputo também existe uma diferenciação de participação em função da zona de residência:

na área urbana, existe uma maneira diferente de pensar e agir. Por exemplo, os jovens podem fazer a diferença através de movimentos sociais e até organizar manifestações usando o Facebook, mas se entrarmos na área sub-urbana, veremos que os jovens são indiferentes a essas situações ${ }^{18}$.

Voltando para 2014, ano em que se realizaram as últimas eleições gerais em Moçambique, tanto os jovens de Maputo, como os da Beira, foram unânimes em afirmar que as redes sociais representaram um "ponto de viragem" para o seguimento das acções dos actores políticos (partidos e candidatos), mas esta acção não teve um impacto substancial na sua decisão final de voto. Ou seja, apesar de terem acompanhado algumas realizações por intermédio das redes sociais (campanha eleitoral), as redes sociais não foram capazes de ser ferramentas mobilizadoras para votar ou para formar a opinião de voto, visto que a decisão de votar (ou não) já estava previamente tomada. Ademais, a partir do nosso estudo foi possível notar que possuir uma conta em uma rede social não é sinónimo de aumento da participação política, mas pode ser o contrário como vários autores críticos sobre participação política online afirmam. Os mesmos

\footnotetext{
${ }^{16}$ Excerto da entrevista a Jackson Timóteo, realizada no dia 9 de Janeiro de 2017, na Cidade da Beira.

${ }^{17}$ Excerto da entrevista a Cídia Chissungo, realizada no dia 9 de Janeiro de 2017, na Cidade de Maputo.

${ }^{18}$ Excerto da entrevista a Alexandre Nhampossa, realizada no dia 4 de Janeiro de 2017, na Cidade de Maputo.
} 
consideram que há uma visão utópica de "mais internet é igual a mais democracia" - o que chamaríamos de miragem democrática.

Outro elemento de destaque alia-se com a qualidade do próprio debate que se registou no seio das redes sociais, tendo sido afirmado que o que se assistiu em 2014 foi o acentuar da polarização de opinião e actos de ataques verbais entre simpatizantes, membros e militantes dos partidos políticos concorrentes, bem como a inexistência de feedback por parte dos actores políticos nos espaços que foram criados para tal interacção durante aquele acto eleitoral, facto que pode ser comprovado com o total abandono de algumas páginas nas redes sociais depois das eleições.

Os jovens das duas cidades notam, com alguma satisfação, que de 2014 a 2017 tenha existido alguma evolução no uso das redes sociais como espaços de participação política, embora prevaleça a apatia generalizada que caracteriza-se pelo "reclamar dentro da caixa", ou seja, a juventude protesta somente nas redes sociais, mas inexiste uma acção enérgica para exprimir a sua vontade desde a última manifestação realizada em 2016 contra o conflito armado em Moçambique. O ano de 2017 não registou nenhuma acção de protesto assinalável.

Como resultado da nossa interacção nas Cidades de Maputo e Beira foi possível perceber que quem mais se engaja nas redes sociais são aqueles que já eram, de certa forma, activos no espaço offline ou que possuíam alguma ligação com uma organização cívica ou uma rede de amigos também activa. Essa tendência é derivada ao elevado nível de desconfiança que se instalou na juventude em relação aos actores políticos nacionais que são vistos como os responsáveis pela situação social degradante em que a juventude urbana se encontra.

Em última análise, a elaboração deste artigo emerge numa época em que Moçambique será palco de eleições autárquicas, sendo que Maputo e Beira voltam a ser os centros urbanos de maior destaque com os actores políticos a prepararem todo o tipo de estratégias para maximizar positivamente o uso das redes sociais como verdadeiros espaços de engajamento político, visto que, de forma recorrente, os jovens encontram nos media digitais um espaço fértil para exprimir a sua opinião e os actores políticos (partidos políticos) não querem se excluir desses espaços.

\section{À GUISA DE CONCLUSÃo}

Falar sobre o uso de redes sociais no espaço urbano pela juventude moçambicana é, em primeiro lugar, considerar que analisamos uma população que representa a maioria dos cerca de 29 milhões de habitantes ${ }^{19}$, sendo que cerca de $60 \%$ é jovem - com idade compreendida entre 18 e 25 anos. Em segundo plano, notamos que a juventude moçambicana está presente nas cidades, mas também nas zonas rurais. Ao todo, uma juventude frequentemente considerada como a "seiva da nação" pelo discurso político moçambicano (Samora Machel, 1977). Entre a apatia e a falta de uma visão comum, é essa juventude que hoje está no centro da mudança da paisagem política, utilizando as

\footnotetext{
19 Informação do INE - Instituto Nacional de Estatísticas de Moçambique, 2017, disponível em http://www.ine.gov.mz/
} 
redes sociais como espaços de participação e mobilização política, concretamente nas "grandes cidades", como são os casos de Maputo, Beira, Quelimane e Nampula.

No entanto, a acentuada desigualdade entre essas cidades em termos de acesso às infra-estruturas de uso da internet, representa um elemento que merece uma atenção especial ao analisar esse tema. Em conexão com essa questão, verifica-se de forma recorrente a disseminação e circulação de notícias falsas (fake news) sobre vários assuntos, bem como o surgimento de um sistema repressivo e autoritário contra as chamadas vozes protestantes contra o regime do partido no poder.

Um dos pontos a considerar nesta conclusão é o debate em torno da compreensão da expressão "ser jovem", um elemento que discutimos ao longo do artigo e demonstramos que não existe um consenso no campo das ciências sociais. A partir do nosso intercâmbio com o público-alvo e da literatura existente, podemos afirmar que ser jovem não é essencialmente uma questão de idade determinada simplesmente por legislação específica de um país, mas é acima de tudo uma condição social e espiritual. Por outro lado, observamos que a determinação de ser jovem é condicionada pelo status de vida de cada individuo no seu ambiente social, político ou económico, uma realidade que também determinará como esse mesmo jovem vai se empenhar no uso das redes sociais como espaços de participação política.

Deve ser enfatizado que, apesar do entusiasmo criado pelas redes sociais em Moçambique, os jovens permanecem como os "conectados abandonados", são esses jovens que representam na sua globalidade a face do desemprego urbano e a precariedade social e económica em Moçambique. Esses mesmos jovens estão nas cidades, mas também nas áreas rurais e usam as redes para "reclamar sem mostrar o rosto" e "sem sair da rede". A esta situação acrescenta-se a individualização das acções que dizem respeito à juventude moçambicana, não há uma missão partilhada sobre os problemas e as necessidades desta camada social, e em último, as desigualdades sociais, económicas e políticas entre jovens da mesma cidade é outro factor que enfraquece a sua mobilização.

\section{REFERÊNCIAS}

Abbink, J. (2004). Being young in Africa: the politics of despair and renewal. Amesterdão: Brill.

Biza, A. (2009). Associações juvenis, Estado e política em Moçambique. Da herança aos novos desafios. Conferência inaugural do IESE, Maputo.

Bordenave, J. (1983). O que é participação. São Paulo: Brasiliense.

Bordes, V. (2004). L'alternative jeunesse. Agora débats/jeunesses, 36, 118-119. Retirado de www.persee.fr/doc/ agora_1268-5666_2004_num_36_1_2183_t13_0118_0000_1

Braud, P. (2014). Sociologie politique. Paris: LDG).

Castells, M. (2001). La galaxie internet. Paris: Fayard.

Chaimite, E. (2017). Das revoltas às marchas: emergência de um repertório de acções collectivas em Moçambique. In L. Brito (Ed.), Agora eles tem medo de nós! (pp. 83-98). Maputo: IESE. 
Coleman, S. (2005). Remixing citizenship: democracy and young people's use of the internet. Research report. Londres: Carnegie Young People Initiative.

Dahlgren, P. (2012). Web et participation politique: quelles promesses et quels pièges? Questions de communication, 21, 13-24. Retirado de https://journals.openedition.org/ questionsdecommunication/6545

De Melo, M. (2013, 13 de novembro). Faire de la politique à l'ère de l'activisme en ligne [Post em blogue]. Retirado de https://blogs.mediapart.fr/marilza-de-melo-foucher/blog/131113/ faire-de-la-politique-l-ere-de-l-activisme-en-ligne

Galland, O. (2009). Les jeunes. Paris: La Découverte.

Gerodimos, R. (2008). Mobilising young citizens in the UK: a content analysis of youth and issue websites. Information, Communication Q Society, 11(7), 964-988. DOI: 10.1080/13691180802109014

Honwana, A. (2012). The time of youth: work, social change and politics in Africa. Londres: Kumarian Press.

Larrouy, P. (2017). Ubérisation: utopie et tyrannie. Paris: Uppr Éditions.

Loader, B. \& Mercea, D. (2011). Networking democracy? Information, Communication Q Society, 14(6), 757-769. DOI: $10.1080 / 1369118 X .2011 .592648$

Luvizotto, C. (2016). Cidadania, ativismo e participação na internet: experiências brasileiras. Comunicação e Sociedade, 30, 297-312. DOI: 10.17231/comsoc.30(2016).2499

Mabi, C. \& Theviot, A. (2014). La rénovation par le web? Dispositifs numériques et évolution du militantisme au PS. Participations, 8, 97-126. DOI: 10.3917/parti.008.0097

Matos. H. (2008). Engagement civique et participation politique: controverses sur les TICs et le déclin du capital social. Les Enjeux de l'information et de la communication, 1, 57-71. Retirado de http://www.cairn. info/article.php?ID_ARTICLE=ENIC_008_0500

Mbembe, A. (1985). Les jeunes et l'ordre politique en Afrique noire. Paris: L'Harmattan.

Monnoyer-Smith, L. (2011). La participation en ligne, révélateur d'une évolution des pratiques politiques?. Participations, 1, 156-185. DOI: 10.3917/parti.001.0156

Morozov, E. (2011). The net delusion: the dark side of internet freedom. Nova lorque: Public Affairs Books.

Muxel, A. (1996). Les jeunes et la politique. Paris: Hachette Livre.

Nay, O. (2014). Lexique de science politique, vie et institutions politiques. Paris: Dalloz.

Norris, P. (2003). Preaching to the converted? Pluralism, participation and party websites. Party Politics, 9(1), 21-45. DOI: $10.1177 / 135406880391003$

Parlamento Juvenil de Moçambique (2014). Juventude e participação política em Moçambique. Maputo: Parlamento Juvenil de Moçambique.

Pereira, M. A. (2011). Internet e mobilização política - os movimentos sociais na era digital. Anais do IV Encontro da Associação Brasileira de Pesquisadores em Comunicação e Política. Retirado de http://www. compolitica.org/home/wp-content/uploads/2011/03/Marcus-Abilio.pdf

Raposo, E. (2012). A centralidade das redes sociais no acesso ao Estado pelos cidadãos. Debates - Boletim Informativo do Centro de Estudos Inter-Disciplinares de Comunicação, 1(1), 4-6. 
Tournier, V. (2009). Comment le vote vient aux jeunes. L'apprentissage de la norme électorale. Agora débats/ jeunesses, 51, 79-96. DOI: 10.3917/agora.051.0079

Vedel, T (2011). Chapitre 5 - L'internet et la démocratie: une liaison difficile. In P. Perrineau \& L. Rouban (Eds.), La démocratie de l'entre-soi (pp. 73-88). Paris: Presses de Sciences Po (P.F.N.S.P.).

\section{NOTA BIOGRÁFICA}

Dércio Tsandzana é licenciado em Administração Pública pela Universidade Eduardo Mondlane, Moçambique. Mestre em Ciência Política pelo IEP Sciences Po Bordeaux, França, sendo que actualmente é doutorando em Ciência Política na mesma Universidade.

Email: dercio.adpub@gmail.com

Morada: Domaine Universitaire, 10 Rue Robert Escarpit, 33600 Pessac, França

* Submetido: 19.05.2018

* Aceite: 20.07 .2018 